\title{
How is your life? understanding the relative importance of life domains amongst older adults, and their associations with self-perceived COVID-19 impacts
}

\author{
Gang Chen ${ }^{1}\left[\right.$ ] Jan Abel Olsen ${ }^{2,3}$ (1) \\ Accepted: 17 November 2021 / Published online: 6 January 2022 \\ (c) The Author(s), under exclusive licence to Springer Nature Switzerland AG 2021
}

\begin{abstract}
Purpose This study aims to provide new knowledge on the relative importance of key life domains amongst older adults, and how the Coronavirus pandemic has influenced their life (domain) satisfaction.

Methods A cross-sectional survey was administrated to an online panel of the general public aged 65 years and older in Australia from 28 April to 26 May 2020. Life satisfaction was measured by the Personal Wellbeing Index (PWI, including both global life satisfaction and life domain satisfaction). A discrete choice experiment technique was used to elicit how respondents perceive the relative importance of six key life domains drawn from the PWI: standard of living, health, relationships, safety, community connectedness, and future security.

Results A total of 1,056 respondents (53\% female) with a mean (range) age of 73 (65-91) years old completed the survey. After controlling for a rich set of confounding factors, regardless of the choice of overall life satisfaction indicators, there were consistent findings that the strongest negative influence of COVID-19 on life domains and decrements on life satisfaction was for Personal Health, Personal Relationships and Standard of Living. The DCE data revealed that all six life domains were statistically significant in contributing to a better life, and there exists some preference heterogeneity between those who perceived no impact versus negative impacts from COVID-19.

Conclusions From both revealed and stated preference data there was robust evidence that health, relationships, and standard of living represent the three most important life domains for older adults in Australia.
\end{abstract}

Keywords COVID-19 $\cdot$ Life satisfaction $\cdot$ Life domain $\cdot$ Discrete choice experiment $\cdot$ Older adults

\section{Plain English summary}

Monitoring and promoting subjective wellbeing for older adults becomes increasingly important. This study helps understand how COVID-19 impact the perceived life changes amongst older adults. We proposed to use pairwise choice questions to elicit the relative importance of key life aspects, and explored the extent to which perceived

Gang Chen

gang.chen@monash.edu

1 Centre for Health Economics, Monash Business School, Monash University, Caulfield East, VIC 3145, Australia

2 Department of Community Medicine, University of Troms $\emptyset$, 9037 Troms $\varnothing$, Norway

3 Division of Health Services, Norwegian Institute of Public Health, 0213 Oslo, Norway
COVID-19 impact influence their preferences. Based on more than 1000 adults aged 65 years and older (53\% female, mean age 73 years old) in Australia, our study showed the perceived influence of the COVID-19 pandemic on eight life domains. Results show that personal health, relationships, and standard of living are three key life aspects that matter the most for older adults in Australia. Policy interventions focusing on maintaining or improving personal health, personal relationships, and standard of living should be prioritised.

\section{Introduction}

The pursuit of wellbeing has become the ultimate aim of public policies in several countries across the world. Life satisfaction is a key component of subjective wellbeing (SWB) and has gained particular attention in public policy 
$[1,2]$. Modelling life satisfaction can reveal the relative strength that people attached to different life aspects and circumstances [3]. Many empirical studies have been conducted to understand the relative importance of different life domains to overall or global life satisfaction over adulthood [4-7].

Over the life course, most empirical studies focused on the whole of adulthood. Increased life expectancy in late adulthood is commonly accompanied by deterioration in health, which further leads older adults to more likely to become dependent [8]. To formulate effective policies towards healthy ageing, it is essential to specifically investigate the relative importance of life domains during late adulthood.

Qualitative analyses have been used to directly understand what life domains contribute to the SWB of older adults, and similar results have been found. Bowling et al. [9] explored what makes older adults' lives good or bad in Britain by analysing responses to a series of open-ended questions. The top three life domains most commonly identified were: social relationships, social roles and activities, and health. When asked the single most important aspect, having good social relationships and having good health ranked equally on top. The importance of these domains was supported by a Dutch study that adopted a different approach [10]. From a total of 15 higher-order domains, social life was ranked on top, followed by activities and health. Although social life was more robustly ranked on top, some heterogeneity was observed, e.g. the second important domain amongst participants aged 75 and older was health, whilst it was activities in the age group 65-74.

The 2019 novel coronavirus disease (COVID-19) outbreak has substantially impacted the daily lives of people across the world [11]. Globally, there is a strong age gradient in the risk of serious illness from COVID-19 [12, 13]. Thus, health authorities have strongly recommended for older adults over 70 years old to self-isolate at home for as long as practicable [14]. However, social isolation could also be a "serious public health concern", in that social disconnection puts older people at greater risk of depression and anxiety [15]. Based on Swedish data, Kivi et al. [16] found that in the early stage of the pandemic, on average, Swedish older adults reported their wellbeing not worse than previous years but those who worried more reported lower wellbeing. Monitoring and promoting the wellbeing of older people in particular during the COVID-19 pandemic becomes increasingly important.

The current study contributes to the literature by proposing to investigate the relative importance of key life domains using a stated preference technique (discrete choice experiment, DCE) that has been widely applied to value health [17] and quality of life aspects [18]. Here our focus goes beyond health. Given the study was conducted during the
COVID-19 pandemic, we have also investigated the relative importance of life domains on life satisfaction using experience data. By far the extensive empirical research on the relative importance of various life domains is primarily based on studies of stable, "status quo" lives. The COVID19 represents an exogenous shock that has a major impact on individuals' wellbeing. Another important contribution in the current study is, therefore, to investigate to what extent an exogenous shock on different life domains affects life satisfaction, and in particular which life domains are hardest hit.

In sum, this study aimed to use both experienced and stated preference (choice experiment) data to reveal a composite picture of how COVID-19 impact the multidimensional life amongst older adults, and to shed light on the relative importance of life domains.

\section{Methods}

\section{Data}

A cross-sectional survey was developed on Qualtrics Survey Software (www.qualtrics.com) and administrated to an online panel of the general public aged 65 years and older in Australia between 28 April to 26 May 2020. ${ }^{1}$ The key survey component was the DCE. The sample size calculation for DCE was difficult given the true preference was unknown prior to the study. Following the previous literature $[17,18]$, a sample size of 1000 respondents would be sufficient for our empirical analyses. The targeting respondents (to be representative concerning age and sex distribution of the Australian general population) were recruited from an online fieldwork company Quality Online Research (QOR) (www.qor.com.au). Differing from other online fieldwork companies, members of the QOR were recruited primarily from offline sources to best represent the Australian population. Members of QOR were invited via email to participate in this study if they met the selection criteria (aged 65 years and over, able to read and respond in the English language, and residing in Australia). Respondents read the explanatory statements and provided consent before participating in the anonymous and voluntary survey. The survey starts with the life satisfaction instrument, perceived COVID-19 impacts and followed by a series of pairwise choice tasks (DCE) to understand preferences amongst different life domains.

\footnotetext{
${ }^{1}$ During this period, the growth in COVID-19 cases stabilised at a low level (on average less than 20 new cases per day) but the economic and social impacts were extensive; more detailed conditions of COVID-19 pandemic in Australia for the recruitment period could be found at https://www.abs.gov.au/articles/measuring-impacts-covid19-mar-may-2020 (Accessed 1 November 2021).
} 
Respondents' background characteristics were collected in the last section.

A post-stratification weight was also created based on sex and age group (65-69 years, 70-74 years, and 75 years and above) post hoc to correct for potential sampling bias according to the Australian Demographic Statistics on estimated resident population (by age and sex at 30 June 2019). The post-stratification weight was applied in the DCE to improve the accuracy and generalizability of the research findings [19].

\section{Measures}

\section{Life satisfaction}

The Personal Wellbeing Index (PWI) is a widely used instrument globally [20, 21]. It contains a single item on global life satisfaction ("Thinking about your own life and personal circumstances, how satisfied are you with your life as a whole?") and life satisfaction on seven key life domains; the standard of living, health, achieving in life, personal relationships, safety, community connectedness, and future security. Each item is scored from 0 "no satisfaction at all" to 10 "completely satisfied". A PWI index can be calculated by taking an average of seven life domain satisfaction scores (Cronbach's alpha $=0.89$, calculated based on the final study sample). In the current study, one further life domain on activities was included given it has been highlighted in the previous qualitative studies mentioned in the Introduction section. The item was drawn from the Study on Global Ageing and Adult Health (SAGE) [22], and adapted to follow the same format as PWI items: "How satisfied are you with your ability to perform your daily living activities?" In the survey following the standard PWI questionnaire the global life satisfaction question was asked first, and the following eight life domains were randomised.

\section{Perceived COVID-19 impacts}

Respondents were asked to self-assess the COVID-19 impact based on the question: "To which extent have any of the following circumstances in your life been affected by the current coronavirus (COVID-19) pandemic over the last few months (since January 2020)", and were offered five responses options: much worse, somewhat worse, about the same (no influence), somewhat better, much better. The eight life domains were listed, and this section ends with the circumstance on "Your life as a whole". In the regression analyses, the perceived negative and positive shocks were combined, i.e. those who answered "much worse" and "somewhat worse" were combined, as well as "somewhat better" and "much better". Before the above questions, respondents were also asked "Are you concerned about coronavirus (COVID-19) in Australia?" with five potential response levels provided, ranging from not at all concerned to extremely concerned.

\section{Perceived COVID-19 impacts on life satisfaction}

The influences of COVID-19 on wellbeing were investigated using the following two equations,

$W B_{m}^{i}=f\left(\operatorname{COVID} 19_{m}^{w}, \operatorname{COVID} 19_{m}^{b}, S_{m}, R, \varepsilon_{m}\right)$

$W B_{m}^{i}=f\left(C O V I D 19_{m}^{D w}, C O V I D 19_{m}^{D b}, S_{m}, R, \varepsilon_{m}\right)$

where $W B$ indicates one of the global wellbeing indicators: $i=1$ if global life satisfaction, and $i=2$ if PWI index is the outcome of interest. COVID $19^{w}$ and COVID $19^{b}$ are two dummy variables that indicate respondents self-assessed their life as a whole been affected by the COVID-19 pandemic over the last few months (since January 2020) as (somewhat/much) worse and (somewhat/much) better, respectively. In this setting, a more neutral reference group was used in the model (i.e. those who perceived their lives to be about the same, or no influence from COVID-19). $C O V$ $I D 19^{D}$ represents the self-assessed impacts from COVID-19 on each of eight life domains, $\mathrm{k}=1, \ldots, 8 . S$ is a vector for respondents' characteristics, $\mathrm{R}$ is a vector for regional characteristics, $\varepsilon$ is an error term, and $f(\bullet)$ indicates an additive functional form, $m$ represents the respondent.

For respondents' characteristics, we control for three sets of information: (i) socio-demographic characteristics (sex, age, whether born in Australia, whether living alone, and whether having any long-term health conditions, impairment or disability); (ii) assessments related to individuals' personality and skills (ability to use the Internet and digital technologies (a proxy for digital literacy), the risk attitude towards health, resilience, and subjective age), and; (iii) regional characteristic regarding social deprivation.

In the survey, respondents self-rated their ability to use the Internet and digital technologies (e.g. mobile apps) in their daily lives. A dummy variable indicating the ability to be acceptable or poor was included in the regression. For risk preference towards health, a self-reported and experimentally validated 11-point Likert scale from the German Socio-Economic Panel was used: "How do you see yourself in relation to your health: are you in general a person who takes risk with your health or do you try to evade risks with your health". The grades run from 0 "not at all prepared to take risk" to 10 "very much prepared to take risk" [23, 24]. Resilience level was measured using a validated 4-item Brief Resilient Coping Scale (BRCS) that was developed to "capture tendencies to cope with stress in a highly adaptive manner" [25]. The question for subjective age was drawn 
Between the following two people, who do you think has a better life?

(all else being equal)

\begin{tabular}{|l|l|l|}
\hline \multicolumn{1}{|c|}{} & \multicolumn{1}{|c|}{ Person A } & \multicolumn{1}{c|}{ Person B } \\
\hline \hline Standard of Living & Very Good & Poor \\
\hline \hline Personal Relationships & Good & Very Poor \\
\hline Personal Safety & Very Poor & Good \\
\hline \hline Future Security & Very Good & Very Poor \\
\hline
\end{tabular}

Person A

Person B

Fig. 1 An example of an implicit partial profile discrete choice experiment task

from the Health and Retirement Study in the US: "Many people feel older or younger than they actually are. What age do you feel? (Write in a number)". A dummy variable was generated to indicate that self-perceived age was $\geq 10$ years younger than chronological age.

Two regional characteristics were controlled. The first is a set of state or territory dummies where respondents reside, and the second one is a relative socio-economic indicator developed by the Australian Bureau of Statistics (ABS) [26] based on respondents' postcode, called Socio-Economic Indexes for Areas (SEIFA). The most recent version of the SEIFA was developed based on Census 2016 data, which consists of four indexes. Amongst them, the Index of Relative Socio-economic Disadvantage (IRSD) is the most general one and differs from the other three, it includes only measures of relative disadvantage within an area. A high IRSD score means a relative lack of disadvantage whilst a low score measure a relatively greater disadvantage in general. The ABS categorised the raw score into 10 deciles, which we grouped it into 5 categories (e.g. the first and second deciles were grouped as the most disadvantaged group, whilst the 9th and the 10th deciles were combined as the least disadvantaged group).

\section{Discrete choice experiments}

\section{Stated preference for life domains importance}

We further elicited the relative importance of life domains via a DCE. In a series of choice tasks, that were described based on hypothetical scenarios using a combination of different life domains and corresponding levels, respondents were asked: "Between the following two people, who do you think has a better life (all else being equal)?" See Fig. 1 for an example of a DCE task.

To construct hypothetical life conditions in DCEs, all life domains were chosen from the PWI with the exclusion of achieving in life. The omission of this domain is mainly because we aim to understand the trade-offs between life domains that could be more explicitly intervened by public policy. The achieving in life domain albeit is one of the most important domains does not fit with the criterion. Consequently, six life domains were used as attributes in the DCE.

The next step was to decide the response levels. The original 0-10 response level from PWI does not fit the choice experiment. After considering some alternatives we chose one from the Quality of Life Enjoyment and Satisfaction Questionnaire (Q-LES-Q) - Short Form. The instrument has five response levels: Very poor, Poor, Fair, Good, Very Good. Given we are more interested to understand the utility range for each attribute (life domain), the middle level was dropped so that the four response levels still maintain the symmetric pattern. This symmetric solution can also be found in the global life satisfaction question ("In general, how satisfied are you with your life? Very satisfied, Satisfied, Dissatisfied, or Very dissatisfied") included in the Behavioural Risk Factor Surveillance System survey (e.g. 2017 Questionnaire, page. 81) in the USA (www.cdc.gov/brfss).

A total of six attributes, each with four levels, resulted in $4096\left(=4^{6}\right)$ possible profiles, and more than 8.3 million possible pairwise choices. To reduce the number of scenarios to a level considered manageable for older adults, an efficient statistical design was employed. A total of 96 choice questions (each with two alternatives) were created and blocked into 12 versions such that each respondent finished 8 choice tasks. To further simplify the choice tasks, instead of 
presenting all six attributes with varying levels, we used an implicit partial profile design such that in each task, respondents only see four attributes with non-overlapping levels. The DCE design was implemented using the Ngene DCE design software (www.choice-metrics.com). The partial profile design was created using a modified Federov algorithm [27]. One limitation of the implicit partial profile design is that only the main effect model can be estimated and the interaction terms between attributes cannot be estimated. Three variations of DCE presentation were originally considered. The final one was chosen after pre-testing online with three adults (see Fig. 1 for an example).

In the DCE section, one example was firstly shown and followed by a warm-up (dominant) choice task in which for a rational decision-maker, a clear option should be chosen. If the respondent failed this dominant task, a message was shown on the screen to explain what the choice means, and to invite the respondent to re-do this dominant task. Upon passing the dominant choice task, the respondent can start to complete eight DCE tasks.

The DCE data were analysed under a random utility theory framework [28]. The utility (U) respondent $m$ derives from choosing alternative $j$ in choice scenario $t$ can be specified as:

$U_{m t j}=x_{m t j}^{\prime} \beta_{m}+\mu_{m t j}$

where $x$ is a vector of observed attributes which were described by life domains and levels, $\beta$ is a vector of coefficients reflecting the desirability of the attributes, and the $\mu$ is the unobserved random error term (assumed to be independent and identically distributed with Gumbel distribution). Effects coding was used for all attributes. A mixed logit model which considers respondents' preference heterogeneity (hereby assuming a normal distribution and estimating a mean coefficient and a standard deviation for each attribute level) was adopted to estimate the utility function [29]. Only the main effect model (i.e. linear additive function form) was considered given we used the implicit partial profile design. The subgroup analyses were conducted according to the age groups of respondents or their perceived COVID-19 impacts. The analyses were conducted in Stata version 16.1 software (StataCorp LP, College Station, TX, USA).

\section{Results}

Initially, a total of 1213 respondents clicked the survey link. Amongst them, 21 respondents did not provide consent and withdrew from the study; a further 136 respondents were excluded owing to two reasons, (a) they did not submit the survey albeit clicked on the link, or (b) the quota was full by the time respondents clicked the link. The final study sample consists of 1056 older adults (53\% female) with a mean (range) age of 73 (65-91) years old. Around 30\% were currently living alone. The vast majority $(80 \%)$ were retired or pensioners, and $70 \%$ had a gross household income of $\$ 65,000$ or below. See Table 1 for detailed respondent characteristics.

Figure 2 presents the percentage of respondents who reported negative, positive or no influence on life domains. Amongst eight domains, the least influenced was health; $11.6 \%$ of respondents reported their health became (somewhat/much) worse owing to COVID-19, whilst only $5.7 \%$ reported better health. The most influenced domain was Community Connectedness; around one third (33.9\%) reported being (somewhat/much) worse. The domain reporting the highest positive effect was Personal Relationships, where $10.6 \%$ reported (somewhat/much) better.

The distribution and mean scores for life satisfaction score on eight life domains are presented in Fig. 3. For the full sample, Personal Relationships (7.9 \pm 2.3$)$, Standard of Living $(7.9 \pm 1.9)$ and Personal Safety $(7.9 \pm 1.8)$ had the highest mean ( \pm standard deviation, SD) scores, whereas Personal Health $(6.8 \pm 2.2)$ and Community Connectedness $(7.0 \pm 2.2)$ had the lowest mean $( \pm \mathrm{SD})$ scores. Statistically significant differences were found on all life domains according to whether they reported receiving negative impacts from COVID-19 on each corresponding domain.

\section{Perceived COVID-19 impacts and life satisfaction}

The associations between the perceived COVID-19 impacts on life as a whole and life satisfaction are reported in Electronic Supplementary Table 1. Those who reported their life as a whole became (somewhat/much) worse were associated with a significant decrement of life satisfaction. The absolute magnitudes of decrement (mean coefficient \pm standard error, SE) were larger when a single item global life satisfaction question was used compared to the PWI index $(-0.095 \pm 0.014$ versus $-0.073 \pm 0.011$, on a $0-1$ scale). For both life satisfaction indicators, those who reported their life became (somewhat/much) better were also associated with higher scores of life satisfaction $(0.026 \pm 0.011$ or $0.031 \pm 0.013$, depending on the outcome indicators).

Regarding the respondents' characteristics such as age; whether respondents were born in Australia; whether living alone; whether have any chronic diseases or disability; risk attitude towards health; resilience, and; subjective age, were all robustly and significantly associated with life satisfaction regardless of measured using a single global life satisfaction question or PWI index. On the contrary, sex and the area disadvantage were insignificant. Results of digital literacy were mixed. A robustness analysis showed that the use of alternative socio-demographic covariates has minimum impacts on 
Table 1 Respondents' characteristics, $N=1056$

\begin{tabular}{|c|c|}
\hline Characteristics & $N(\%)$ \\
\hline \multicolumn{2}{|l|}{$\operatorname{Sex}$} \\
\hline Female & $556(52.7)$ \\
\hline Age, mean (SD) (years) & $73.0(5.6)$ \\
\hline $65-69$ & $342(32.4)$ \\
\hline $70-74$ & $301(28.5)$ \\
\hline $75+$ & $413(39.1)$ \\
\hline \multicolumn{2}{|l|}{ Marital status } \\
\hline Married/De facto/In a relationship & $694(65.7)$ \\
\hline Widowed & $142(13.4)$ \\
\hline Single (never married) & $66(6.3)$ \\
\hline Divorced/Separated & $154(14.6)$ \\
\hline \multicolumn{2}{|l|}{ Living arrangement } \\
\hline With a spouse/partner \& children & $89(8.4)$ \\
\hline With a spouse/partner without children & $577(54.6)$ \\
\hline Alone & $311(29.5)$ \\
\hline Other & $79(7.5)$ \\
\hline Household size, mean (SD) (persons) & $1.90(1.05)$ \\
\hline Born in Australia & $771(73.0)$ \\
\hline Self-reported socioeconomic status ${ }^{\mathrm{a}}$, mean (SD) & $6.7(1.6)$ \\
\hline Self-reported health risk attitude ${ }^{\mathrm{b}}$, mean (SD) & $3.2(2.5)$ \\
\hline No chronic disease or disability & $319(30.2)$ \\
\hline \multicolumn{2}{|l|}{ Self-reported health } \\
\hline Excellent/Very good & $395(37.4)$ \\
\hline Good & $386(36.6)$ \\
\hline Fair/Poor & $275(26.0)$ \\
\hline Resilience $^{\mathrm{c}}$, mean (SD) & $14.8(3.0)$ \\
\hline Low (BRCS: 4-13) & $327(31.0)$ \\
\hline Medium (BRCS: 14-16) & $461(43.6)$ \\
\hline High (BRCS: 17-20) & $268(25.4)$ \\
\hline \multicolumn{2}{|l|}{ Subjective age as compared to chronological age ${ }^{\mathrm{d}}$} \\
\hline Younger than $\geq 10$ years & $573(54.3$ \\
\hline Similar (within 10 years difference) & $447(42.3)$ \\
\hline Older than $\geq 10$ years & $36(3.4)$ \\
\hline \multicolumn{2}{|c|}{ Ability to use the Internet and digital technologies in daily lives (digital literacy) } \\
\hline Very good & $360(34.1)$ \\
\hline Good & $379(35.9)$ \\
\hline Acceptable/poor & $317(30.0)$ \\
\hline \multicolumn{2}{|l|}{ Education } \\
\hline University bachelor degree and above & $260(24.6)$ \\
\hline Diploma/certificate & $401(38.0)$ \\
\hline Secondary school or below & $395(37.4)$ \\
\hline \multicolumn{2}{|l|}{ Employment } \\
\hline Retired/pensioner & $845(80.0)$ \\
\hline Full-time/part-time employed & $126(11.9)$ \\
\hline Other & $85(8.1)$ \\
\hline \multicolumn{2}{|l|}{ Gross household income in last financial year } \\
\hline$\$ 65,001$ and above (high income) & $270(25.6)$ \\
\hline$\$ 35,001-\$ 65,000$ (middle income) & $388(36.7)$ \\
\hline$\$ 35,000$ or below (Low income) & $350(33.1)$ \\
\hline Unknown/missing & $48(4.6)$ \\
\hline Index of Relative Socio-economic Disadvantage (IRSD), mean (SD) & $997.6(66.1)$ \\
\hline
\end{tabular}


Table 1 (continued)

\begin{tabular}{lc}
\hline Characteristics & $N(\%)$ \\
\hline Most disadvantage (1st \& 2nd deciles) & $206(19.5)$ \\
Below average (3rd \& 4th deciles) & $195(18.5)$ \\
Average group (5th \& 6th deciles) & $225(21.3)$ \\
Above average (7th \& 8th deciles) & $196(18.5)$ \\
Least disadvantage (9th \& 10th deciles) & $234(22.2)$ \\
Concerned about COVID-19 in Australia & \\
Not at all/slightly & $276(26.1)$ \\
Moderately & $337(31.9)$ \\
Significantly/extremely & $443(42.0)$ \\
States & \\
NSW & $305(28.9)$ \\
VIC & $274(26.0)$ \\
QLD & $231(21.9)$ \\
WA & $106(10.0)$ \\
SA & $98(9.2)$ \\
Other states & $42(4.0)$ \\
\hline
\end{tabular}

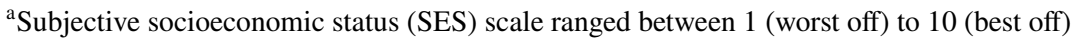

${ }^{\mathrm{b}}$ The scale ranged between 0 (not at all prepared to take risk) and 10 (very much prepared to take risk)

${ }^{\mathrm{c}}$ The 4-item Brief Resilient Coping Scale (BRCS), ranged from 4 (low resilience) to 20 (high resilience)

${ }^{\mathrm{d}}$ The subjective age refers to the age that a respondent felt about herself/himself

Fig. 2 Perceived COVID-19 impacts on life domains and life as a whole, $\%$

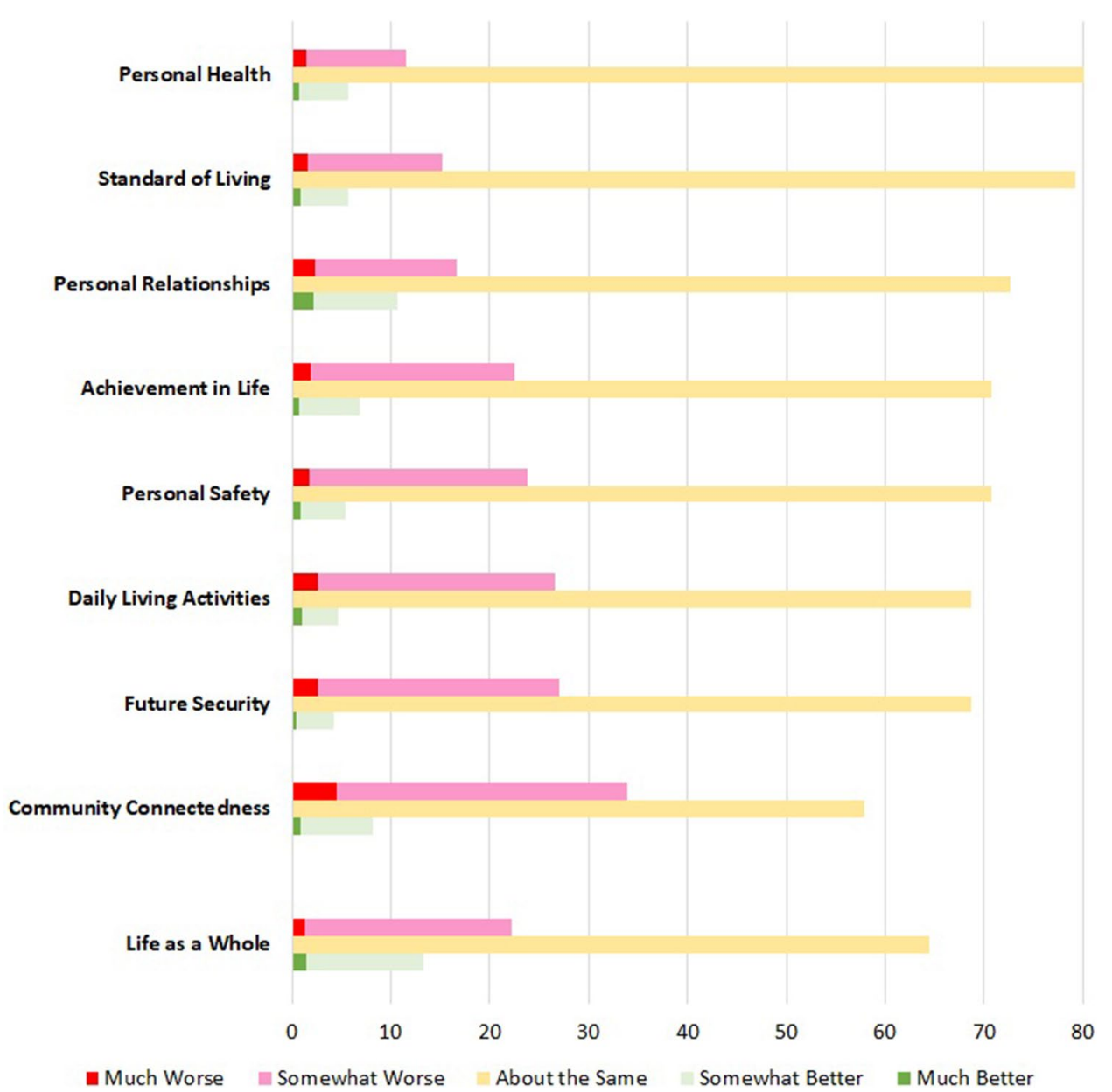




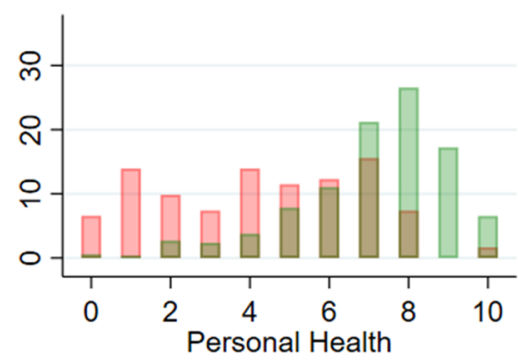

M(SD): F-6.8(2.2); W-4.3(2.6); S-7.1(1.9)
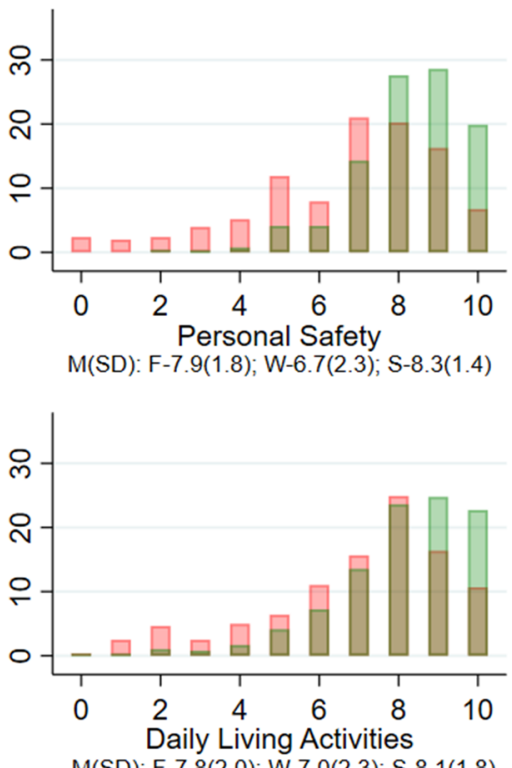

M(SD): F-7.8(2.0); W-7.0(2.3); S-8.1(1.8)
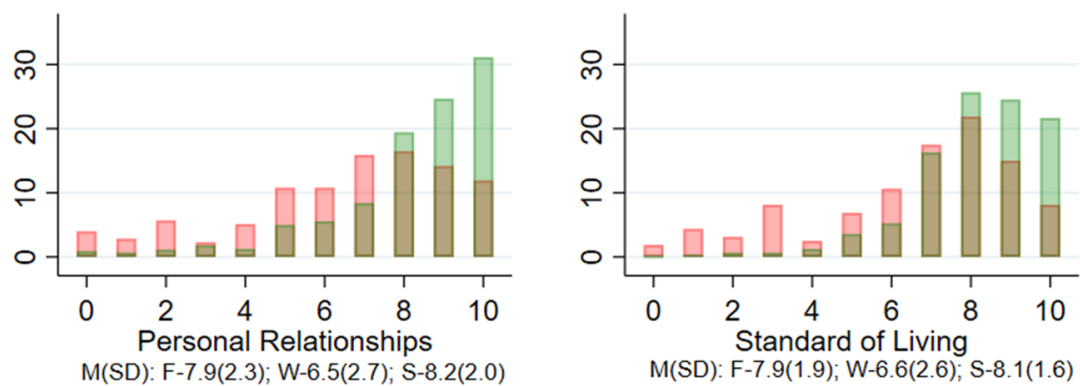

M(SD): F-7.9(1.9); W-6.6(2.6); S-8.1(1.6)

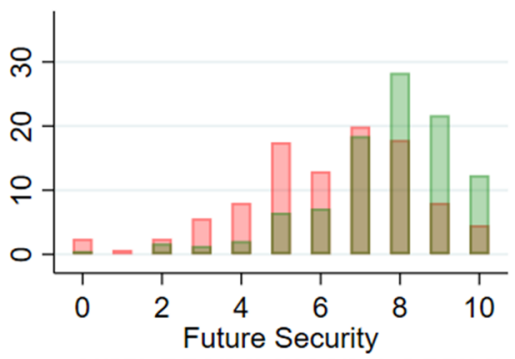

M(SD): F-7.3(2.0); W-6.2(2.2); S-7.7(1.8)

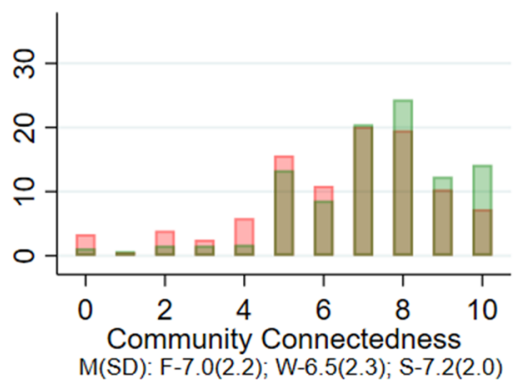

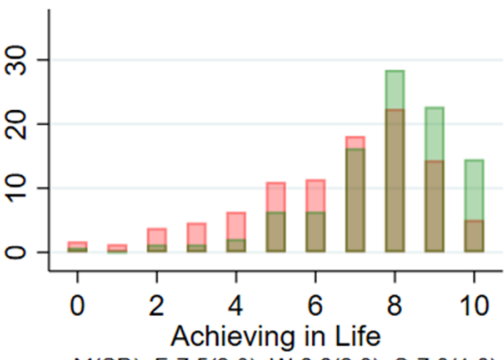

$\mathrm{M}(\mathrm{SD})$ : F-7.5(2.0); W-6.6(2.3); S-7.8(1.8)

Worse (in corresponding domain) Same/Better (in corresponding domain)

Note: Y-axis: percent; $\mathrm{X}$-axis: life domain satisfaction. $M(S D)$, Mean (standard deviation); $F$, full sample;

W, worse owing to COVID-19 pandemic;

$\mathrm{S}$, same or better owing to COVID-19 pandemic;

Mann-Whitney test: $\mathrm{W}$ vs $\mathrm{S}(\mathrm{P}<0.01$ in all domains).

Fig. 3 Distribution of life domain satisfaction scales (0-10 scale)

the results (see Electronic Supplementary Table 2, including its footnote for details on the alternative covariates used).

Table 2 further investigated the influences of each life domain. In the global life satisfaction equation, four out of eight life domains were statistically significant: the Standard of Living domain had the largest magnitude of decrements on satisfaction with life as a whole $(-0.069 \pm 0.018)$, followed by Personal Relationships $(-0.064 \pm 0.016)$, Personal Health $(-0.061 \pm 0.021)$ and Achievement in Life $(-0.037 \pm 0.015)$. When the PWI index was used as the outcome measure, two additional life domains were statistically significant; besides, the ranking of decrement magnitudes changed to Personal Health the largest $(-0.071 \pm 0.016)$, followed by Personal Relationships $(-0.064 \pm 0.012)$, Standard of Living $(-0.047 \pm 0.014)$, Personal Safety $(-0.036 \pm 0.010)$, Future Security $(-0.032 \pm 0.010)$, and Achievement in Life $(-0.023 \pm 0.011)$.

\section{Stated preference for life domains importance}

The relative importance of life domains from DCEs is presented in Table 3. All six life domains were statistically significant, and the estimated coefficients for dimension levels all demonstrated the expected monotonicity. For all life domains, the poor and very poor conditions were found to have negative latent utility values whilst the good and very good conditions showed positive latent utility values. Within each attribute, the estimated significant standard deviations of some response levels indicate the existence of some preference heterogeneity amongst respondents. Based on the utility ranges of each life domain (i.e. the difference between the latent utilities of the best level ("Very Good") and the worst level ("Very Poor")), we can see that Personal Health ranked the top amongst six life domains, followed by Personal Relationships, Standard of Living, Personal Safety, Future Security, and Community Connectedness.

Figure 4 shows the relative importance of life domains when analyzing four sub-groups separately, three age groups (65-69, 70-74, and 75 plus), and to what extent respondents rated life as a whole were about the same versus those who perceived negative shocks owing to the COVID-19 pandemic. A subgroup who stated they were significantly or extremely concerned about COVID-19 were also included in the comparison. Figure 4A demonstrated fairly consistent 
Table 2 Association between perceived COVID-19 Impact and life satisfaction

\begin{tabular}{|c|c|c|c|c|}
\hline & \multicolumn{2}{|c|}{$\begin{array}{l}\text { Global life satis- } \\
\text { faction }\end{array}$} & \multicolumn{2}{|c|}{ PWI index } \\
\hline & Coeff & SE & Coeff & SE \\
\hline \multicolumn{5}{|c|}{$\begin{array}{l}\text { Perceived negative Impact of COVID-19 on each life domain, Ref.: } \\
\text { No influence (on each life domain) }\end{array}$} \\
\hline \multicolumn{5}{|c|}{ Life domains } \\
\hline Standards of living & -0.069 & $(0.018)^{* *}$ & -0.047 & $(0.014)^{* *}$ \\
\hline Personal relationships & -0.064 & $(0.016)^{* *}$ & -0.064 & $(0.012)^{* *}$ \\
\hline Personal health & -0.061 & $(0.021)^{* *}$ & -0.071 & $(0.016)^{* *}$ \\
\hline Achievement in life & -0.037 & $(0.015)^{*}$ & -0.023 & $(0.011)^{*}$ \\
\hline Personal safety & -0.015 & $(0.012)$ & -0.036 & $(0.010)^{* *}$ \\
\hline Future security & -0.013 & $(0.013)$ & -0.032 & $(0.010)^{* *}$ \\
\hline Community connectedness & -0.017 & $(0.012)$ & -0.010 & $(0.009)$ \\
\hline $\begin{array}{l}\text { Ability to perform daily } \\
\text { living activities }\end{array}$ & -0.016 & $(0.013)$ & -0.010 & $(0.010)$ \\
\hline Respondent characteristics & $\checkmark$ & & $\checkmark$ & \\
\hline Regional characteristics & $\checkmark$ & & $\checkmark$ & \\
\hline Observations & 1056 & & 1056 & \\
\hline R-squared & 0.308 & & 0.410 & \\
\hline
\end{tabular}

Robust standard errors (SEs) in parentheses. ${ }^{* *} p<0.01,{ }^{*} p<0.05$. Two dependent variables in this table include (1) a global life satisfaction scale in the Personal Wellbeing Index (PWI), "Thinking about your own life and personal circumstances, how satisfied are you with your life as a whole?", and (2) the PWI index; both two dependent variables were re-scaled onto $0-1$ scale where higher scores indicate higher levels of life satisfaction. Control variables also include a set of dummies that indicate respondents perceived positive shocks from COVID-19 on each life domain (all $P>0.1$ ). Respondent and regional characteristics include in each model see Electronic Supplementary Table 1. In brief, respondent characteristics include sex, age, whether born in Australia, whether living alone, whether having any longterm health conditions, impairment or disability, digital literacy, risk attitude towards health, resilience and subjective age. Regional characteristics include a set of Index of Relative Socio-economic Disadvantage dummies and a set of State/territory dummies

preferences amongst the three age groups. In Fig. 4B, some preference heterogeneity was observed. Compared to those who perceived no impact from COVID-19, the ranking between Standard of Living and Personal Relationship switched (now ranked the second and third, respectively) amongst those who self-reported their life been negatively impacted by COVID-19. Community Connectedness and Future Security now become the fifth and the least important ones, respectively, which can also be seen amongst those who are significantly/extremely concerned about COVID-19.
Table 3 Relative importance of life domains from discrete choice experiments, mixed logit estimates

\begin{tabular}{|c|c|c|c|c|}
\hline \multirow[b]{2}{*}{ Life domains } & \multicolumn{2}{|l|}{ Mean } & \multicolumn{2}{|c|}{ Standard deviation } \\
\hline & Coefficient & SE & Coefficient & SE \\
\hline \multicolumn{5}{|l|}{ Standard of living } \\
\hline Very poor (Ref.) & -1.426 & $(0.118)^{* *}$ & & \\
\hline Poor & -0.980 & $(0.083)^{* *}$ & 0.144 & $(0.297)$ \\
\hline Good & 1.064 & $(0.094)^{* *}$ & 0.693 & $(0.146)^{* *}$ \\
\hline Very good & 1.342 & $(0.106)^{* *}$ & 0.530 & $(0.133)^{* *}$ \\
\hline \multicolumn{5}{|l|}{ Personal health } \\
\hline Very poor (Ref.) & -2.581 & $(0.183)^{* *}$ & & \\
\hline Poor & -1.055 & $(0.090)^{* *}$ & 0.394 & $(0.150)$ \\
\hline Good & 1.428 & $(0.117)^{* *}$ & 0.716 & $(0.122)^{* *}$ \\
\hline Very good & 2.208 & $(0.160)^{* *}$ & 1.172 & $(0.129)^{* *}$ \\
\hline \multicolumn{5}{|l|}{$\begin{array}{l}\text { Personal relation- } \\
\text { ships }\end{array}$} \\
\hline Very poor (Ref.) & -1.317 & $(0.106)^{* *}$ & & \\
\hline Poor & -1.062 & $(0.094)^{* *}$ & 0.519 & $(0.148)^{* *}$ \\
\hline Good & 0.834 & $(0.084)^{* * *}$ & 0.418 & $(0.151)^{* *}$ \\
\hline Very good & 1.545 & $(0.112)^{* *}$ & 0.675 & $(0.119)^{* *}$ \\
\hline \multicolumn{5}{|l|}{ Personal safety } \\
\hline Very poor (Ref.) & -1.285 & $(0.110)^{* *}$ & & \\
\hline Poor & -0.797 & $(0.075)^{* *}$ & 0.024 & $(0.081)$ \\
\hline Good & 0.897 & $(0.082)^{* *}$ & 0.439 & $(0.174)^{*}$ \\
\hline Very good & 1.185 & $(0.092)^{* *}$ & 0.379 & $(0.171)^{*}$ \\
\hline \multicolumn{5}{|l|}{$\begin{array}{l}\text { Community connect- } \\
\text { edness }\end{array}$} \\
\hline Very poor (Ref.) & -0.945 & $(0.083)^{* *}$ & & \\
\hline Poor & -0.524 & $(0.075)^{* *}$ & 0.003 & $(0.196)$ \\
\hline Good & 0.541 & $(0.070)^{* *}$ & 0.021 & $(0.082)$ \\
\hline Very good & 0.928 & $(0.091)^{* *}$ & 0.472 & $(0.132)^{* *}$ \\
\hline \multicolumn{5}{|l|}{ Future security } \\
\hline Very poor (Ref.) & -1.096 & $(0.099)^{* *}$ & & \\
\hline Poor & -0.912 & $(0.081)^{* *}$ & 0.025 & $(0.127)$ \\
\hline Good & 0.938 & $(0.083)^{* *}$ & 0.347 & $(0.138)^{*}$ \\
\hline Very good & 1.070 & $(0.094)^{* *}$ & 0.425 & $(0.152)^{* *}$ \\
\hline $\mathrm{N}$ & 16,896 & & & \\
\hline Observations & 1056 & & & \\
\hline Log likelihood & -2965 & & & \\
\hline
\end{tabular}

Robust standard errors (SEs) in parentheses. ${ }^{* *} p<0.01,{ }^{*} p<0.05$. Effect coding was used for all attributes. For all random coefficients, normal distribution was used and they were assumed to be independent. The significant standard deviation of attribute levels indicates the existence of preference heterogeneity of those attribute levels. 1000 Halton draws were used for the simulation. Amongst respondents, $46 \%$ regarded completing the DCE task to be (very) easy, $32 \%$ neither easy nor difficult, $20 \%$ difficult and $2 \%$ very difficult

A post-stratification weight was applied. It was calculated based on Australian Demographic Statistics, Dec 2019 (Table 8 Estimated resident population, by age and sex at 30 June 2019) (https://www.abs. gov.au/ausstats/abs@.nsf/mf/3101.0; Accessed 30 July 2020) 
Fig. 4 The relative importance of six life domains based on discrete choice experiments, $\%$

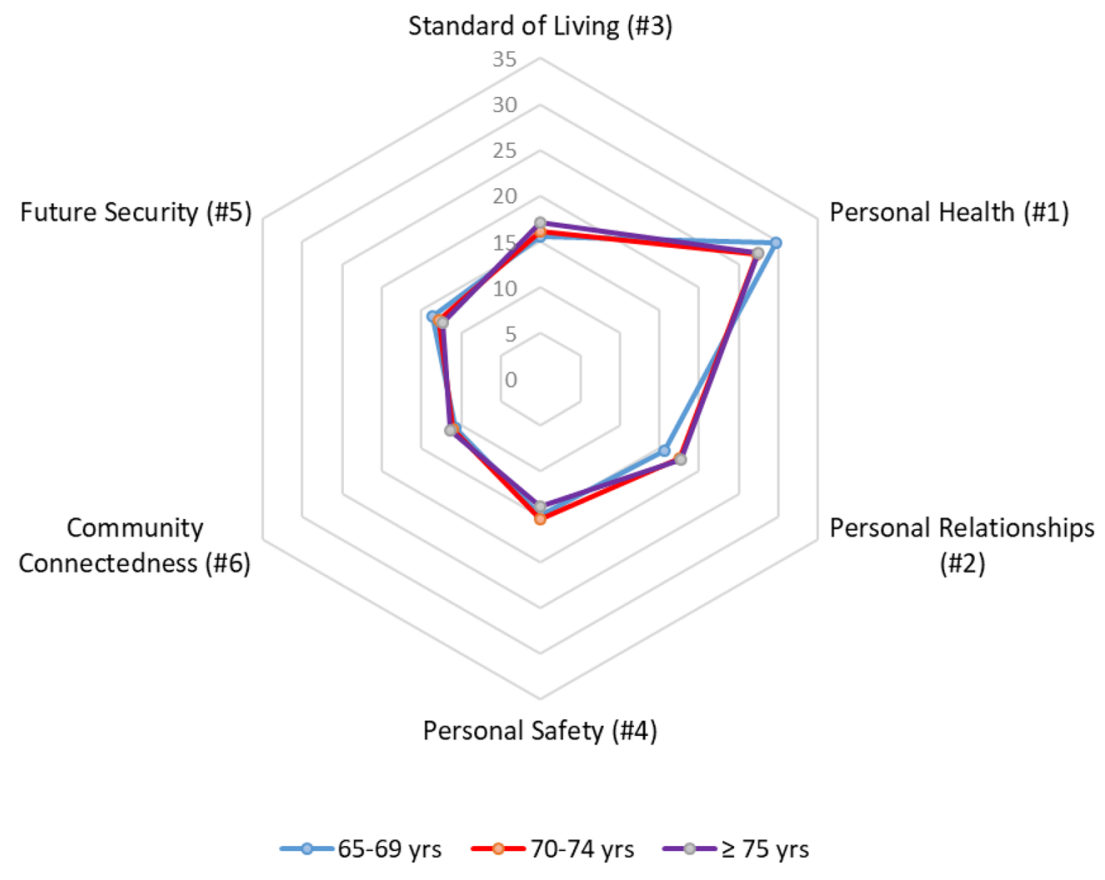

(A)

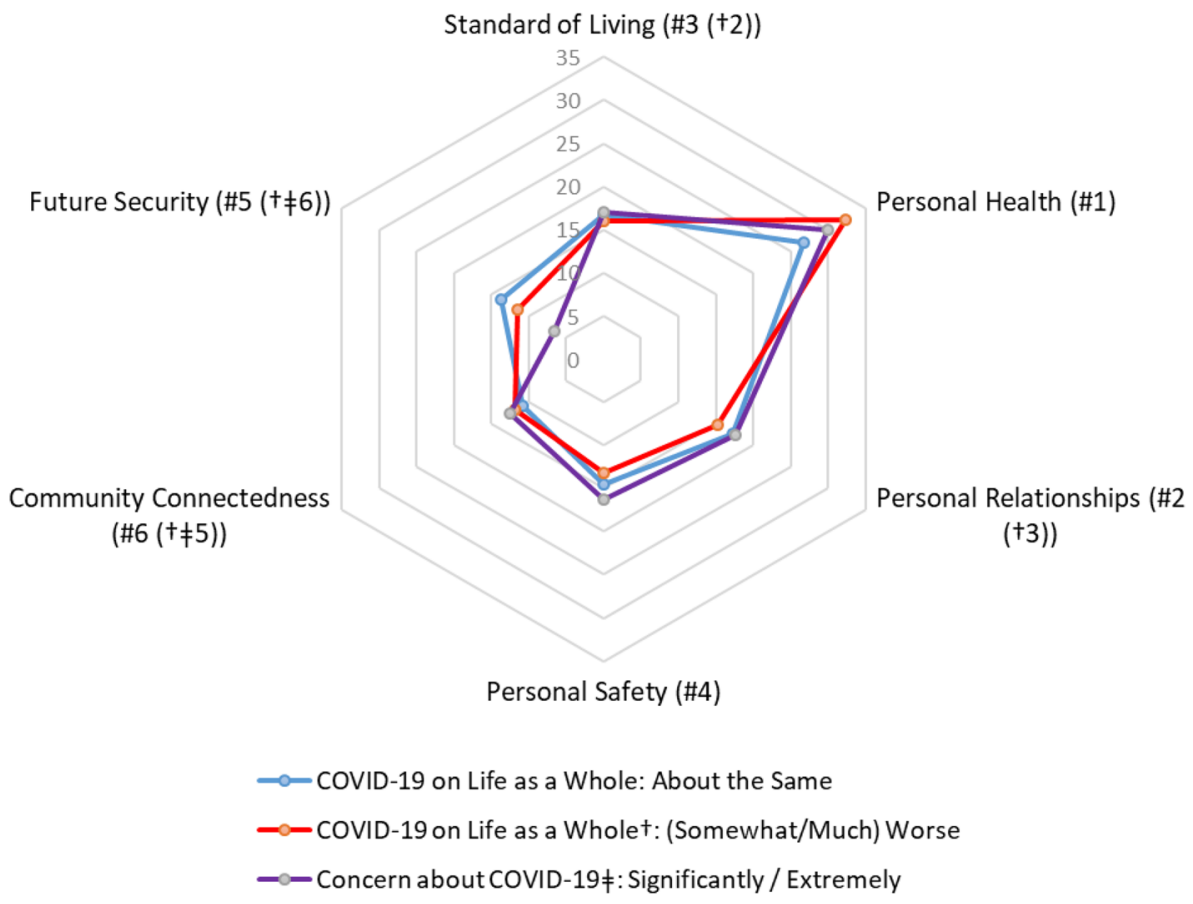

(B)

\section{Discussion}

Life satisfaction is regarded as a key indicator of successful aging. Based on an online panel with more than 1000 adults aged 65 years and older in Australia, this study comprehensively examined the external shock of COVID-19 on life satisfaction as well as the relative importance of key life domains amongst older people. We found that under the COVID-19 pandemic, those who perceived negative shocks were significantly associated with lower life satisfaction scores. To reduce potential issues with omitted-variable bias and response bias (or measurement bias), we have controlled for a rich set of individual and regional characteristics, and the conclusion is robust to different model specifications. 
Regarding respondents' characteristics, not unique during the COVID-19 pandemic, building and promoting resilience and neurocognitive health be beneficial for the healthy ageing of older adults. It should be noted that individual risk preferences are moderately stable over time [30], whilst a health shock and bad economic news make people (temporarily) more risk-averse [31, 32]. As shown in this study, the shocks from COVID-19 go beyond health, and it is unclear to what extent the pandemic had impacted respondents' risk preference by the time of the survey.

It is important to note from experienced data that the relative importance of life domains varied when comparing the regression results on analysing the changes on life domains owing to COVID-19 pandemic on overall life satisfaction (Table 2) versus the likelihood that participants reported negative influences on each life domain (Fig. 2). Regardless of the choice of overall life satisfaction indicators, there were consistent findings that the strength of associations between perceived negative influence on life domains and decrements on life satisfaction was the strongest for three domains (ranked by the average coefficients in two life satisfaction equations): Personal Health, Personal Relationships and Standard of Living. On the other hand, Community Connectedness and Ability to Perform Daily Living Activities were the weakest associated two life domains. This ranking differs dramatically from the results shown in Fig. 2, in which Personal Health, Standard of Living and Personal Relationships were three domains that were less likely to perceive negative impacts, whilst Community Connectedness was the life domain that most likely to perceive negative influence during COVID-19 pandemic.

The stated preference data, based on hypothetical scenarios, further provided a unique source to understand what life domains matter most for older adults. The top three are consistent with revealed preference based on the experienced data: Personal Health was the most important one, followed by Personal Relationship and Standard of Living (Table 3). The rankings are consistent when analyzing three age groups separately suggesting a relatively stable preference amongst older adults. Given the timing of the survey and the position of the choice experiments in the survey, although the DCE task was not specifically asking respondents to tell us which life domains matter the most during the COVID-19 pandemic, the results nevertheless cannot rule out the COVID19 impact. If analysing those who reported their life as a whole were (somewhat/much) worse owing to COVID-19, we see that the utility range of the Personal Health domain become larger (32\% vs $27 \%$ in the full sample). Although the relative rankings of some life domains switched the magnitudes of utility ranges were very close to each other (Fig. 4).

Table 3 shows some interesting differences across life domains with respect to identifying diminishing marginal utilities across the levels (a visual presentation see Electronic
Supplementary Fig. 1). For example, for Standard of Living, there is a low marginal utility by moving from Good to Very Good $(1.342-1.064=0.278)$, whilst for Personal Health and Personal Relationships, the corresponding marginal utilities are three times higher; 0.780 and 0.711 , respectively. Note also the differences across domains at the lower end of the scale, e.g. the extremely high marginal utility associated with moving from Very Poor to Poor in Personal Health $(-1.055$ $--2.581=1.526$ ).

Consistent with previous qualitative literature, health and relationships are two domains that have been ranked highly [9]. Activities domain has also been found to be ranked highly by older adults. Although this domain was not included in the PWI, we have added it in the survey and analysed it in the experience data. In this study, however, it was one of the least important domains (consistently insignificant in Table 2). Regarding the other empirical evidence amongst older adults, Henchoz et al. [33] found that in Switzerland, amongst seven life domains, the most important one was feeling of safety, followed by health and mobility, autonomy, whilst the least important one was social and cultural life. The above differences may be owing to the different methods been used, the timing of the survey, as well as the existence of country heterogeneity. A cross-country analysis conducted under the same analytical framework would be helpful to understand how institutional or cultural differences affect the relative importance of life domains.

This study has several caveats when interpreting its findings. First, the potential limitations of using online panel members have been discussed in the literature [34]. It is the most feasible approach to recruit a large number of respondents during the COVID-19 pandemic, which has been widely adopted in health and social science-related research in Australia [35, 36]. Second, this is a cross-sectional survey, although we have tried to control for a rich set of individual characteristics, there could still be some unobservable individual characteristics that influence both the self-perceived COVID-19 impact and life satisfaction outcomes. Furthermore, the perceived impact was retrospectively evaluated which may be subject to recall bias [37]. Third, to reduce the response burden of DCE tasks, we used an implicit partial profile design, and consequently, only the main effects can be estimated. However, purely using the main effect function is not uncommon in the literature developing preference weights for HRQoL instruments [36, 38]. Fourth, this study was conducted in Australia and further cross-country comparison studies are required to understand the generalisability of the study results.

Bearing all the above limitations, this study still makes significant contributions to understanding the impact of COVID19 on subjective wellbeing, and, more generally, to the literature explaining the relative importance of life domains. The DCE estimates on key life domains further provide the basis 
to create a preference-based wellbeing index that goes beyond health.

\section{Conclusions}

The COVID-19 pandemic has significantly influenced the life satisfaction of older adults. Based on more than 1000 adults aged 65 years and older in Australia, this study revealed to what extent the COVID-19 pandemic has impacted people's perceived multidimensional lives. The relative importance of key life domains on life satisfaction was revealed based on comprehensive empirical analyses from both experienced and stated preference data. Overall, robust evidence indicated that personal health, personal relationships, and standard of living are three key life domains that matter the most for older adults in Australia.

Supplementary Information The online version contains supplementary material available at https://doi.org/10.1007/s11136-021-03043-5.

Author contributions Both authors contributed to the study conception and design. Data collection and analysis were performed by CG. The first draft of the manuscript was written by CG and both authors contributed to the revisions of the manuscript. Both authors read and approved the final manuscript.

Funding The study was supported by the Monash Business School Centre for Development Economics and Sustainability (CDES) through the COVID-19 Grant. Associate Professor Gang Chen is the recipient of an Australian Research Council Discovery Early Career Researcher Award (Project Number DE180100647) funded by the Australian Government.

Data availability The dataset generated during the current study are not publicly available due to privacy or ethical restrictions but are available from the corresponding author on reasonable request.

Code availability The code used to analyse the current study are available from the corresponding author.

\section{Declarations}

Conflict of interest Both authors declare that they have no competing interests.

Ethical approval The study has been approved by the Monash University Human Research Ethics Committee, Monash University, Australia (Project ID: 24402).

Consent to participate All participants were informed about and agreed to participate in this study via an online consent form.

Consent for publication All participants were informed that the results of this study will be submitted for publications in research journals and agreed to participate in this study.

\section{References}

1. Whiteley, P., Clarke, H. D., Sanders, D., \& Stewart, M. C. (2010). Government performance and life satisfaction in contemporary Britain. Journal of Politics, 72, 733-746.

2. Frey, B. S., \& Stutzer, A. (2002). What can economists learn from happiness research? Journal of Economic Literature, 40, 402-435.

3. Diener, E., Inglehart, R., \& Tay, L. (2013). Theory and validity of life satisfaction scales. Social Indicators Research, 112, 497-527.

4. van Praag, B. M. S., Frijters, P., \& Ferrer-i-Carbonell, A. (2003). The anatomy of subjective well-being. Journal of Economic Behavior \& Organization, 51, 29-49.

5. Easterlin, R. A. (2006). Life cycle happiness and its sources: Intersections of psychology, economics, and demography. Journal of Economic Psychology, 27, 463-482.

6. McAdams, K. K., Lucas, R. E., \& Donnellan, M. B. (2012). The role of domain satisfaction in explaining the paradoxical association between life satisfaction and age. Social Indicators Research, 109, 295-303.

7. Bardo, A. R. (2017). A life course model for a domains-oflife approach to happiness: Evidence from the United States. Advances in Life Course Research, 33, 11-22.

8. Larkin, M. (2013). Health and well-being across the life course. Sage Publications.

9. Bowling, A., Gabriel, Z., Dykes, J., Dowding, L. M., Evans, O., Fleissig, A., et al. (2003). Let's ask them: A national survey of definitions of quality of life and its enhancement among people aged 65 and over. The International Journal of Aging and Human Development, 56, 269-306.

10. Douma, L., Steverink, N., Hutter, I., \& Meijering, L. (2017). Exploring subjective well-being in older age by using participant-generated word clouds. The Gerontologist, 57, 229-239.

11. Galea, S., Merchant, R. M., \& Lurie, N. (2020). The mental health consequences of COVID-19 and physical distancing: The need for prevention and early intervention. JAMA Internal Medicine, 180, 817-818.

12. Holt, N.R., Neumann, J.T., McNeil, J.J., Cheng, A. (2020). Implications of COVID-19 in an ageing population. Medical Journal of Australia. https://www.mja.com.au/journal/2020/ implications-covid-19-ageing-population

13. Zheng, Z., Peng, F., Xu, B., Zhao, J., Liu, H., Peng, J., et al. (2020). Risk factors of critical \& mortal COVID-19 cases: A systematic literature review and meta-analysis. Journal of Infection. https://doi.org/10.1016/j.jinf.2020.04.021

14. Brooke, J., \& Jackson, D. (2020). Older people and COVID19: Isolation, risk and ageism. Journal of Clinical Nursing, 29, 2044-2046.

15. Armitage, R., \& Nellums, L. B. (2020). COVID-19 and the consequences of isolating the elderly. The Lancet Public health, $5, \mathrm{e} 256$.

16. Kivi, M., Hansson, I., Bjälkebring, P. (2020). Up and about: Older adults' well-being during the COVID-19 pandemic in a Swedish longitudinal study. Journals of Gerontology: Series B, gbaa084.

17. Stolk, E. A., Oppe, M., Scalone, L., \& Krabbe, P. F. M. (2010). Discrete choice modeling for the quantification of health states: The case of the EQ-5D. Value in Health, 13, 1005-1013.

18. Mulhern, B., Norman, R., De Abreu Lourenco, R., Malley, J., Street, D., \& Viney, R. (2019). Investigating the relative value of health and social care related quality of life using a discrete choice experiment. Social Science \& Medicine, 233, 28-37.

19. Royal, K. (2019). Survey research methods: A guide for creating post-stratification weights to correct for sample bias. Education in the Health Professions, 2, 48-50. 
20. Cummins, R. A. (1998). The second approximation to an international standard for life satisfaction. Social Indicators Research, $43,307-334$.

21. International Wellbeing Group. (2013). Personal wellbeing index (5th ed.). Australian Centre on Quality of Life, Deakin University.

22. World Health Organization. (2006). WHO SAGE survey manual: The WHO Study on Global AGEing and Adult Health (SAGE). Geneva, World Health Organization. https://www.who.int/healt hinfo/survey/SAGESurveyManualFinal.pdf. Accessed 27 Mar 2020.

23. Wagner, G.G., Frick, J.R., Schupp, J. (2007). The German SocioEconomic Panel Study (SOEP) - Evolution, scope and enhancements. SOEPpaper, No. 1, Available at https://doi.org/10.2139/ ssrn.1028709.

24. Dohmen, T., Huffman, D., Schupp, J., Falk, A., Sunde, U., \& Wagner, G. G. (2011). Individual risk attitudes: Measurement, determinants, and behavioral consequences. Journal of the European Economic Association, 9, 522-550.

25. Sinclair, V. G., \& Wallston, K. A. (2004). The development and psychometric evaluation of the Brief Resilient Coping Scale. Assessment, 11, 94-101.

26. Australian Bureau of Statistics. (2018). Technical paper: SocioEconomic Indexes for Areas (SEIFA) 2016. ABS Catalogue No. 2033.0.55.001. Canberra: Commonwealth of Australia.

27. ChoiceMetrics. (2018). Ngene 1.2 user manual \& reference guide. ChoiceMetrics.

28. Louviere, J. J., Hensher, D. A., \& Swait, J. D. (2000). Stated choice methods: Analysis and applications. Cambridge University Press.

29. Hole, A. R. (2007). Fitting mixed logit models by using maximum simulated likelihood. Stata Journal, 7, 388-401.

30. Schildberg-Hörisch, H. (2018). Are risk preferences stable? Journal of Economic Perspectives, 32, 135-154.
31. Decker, S., \& Schmitz, H. (2016). Health shocks and risk aversion. Journal of Health Economics, 50, 156-170.

32. Tausch, F., \& Zumbuehl, M. (2018). Stability of risk attitudes and media coverage of economic news. Journal of Economic Behavior \& Organization, 150, 295-310.

33. Henchoz, Y., Meylan, L., Goy, R., Guessous, I., Bula, C., Demont, M., et al. (2015). Domains of importance to the quality of life of older people from two Swiss regions. Age and Ageing, 44, 979-985.

34. Matthijsse, S. M., \& LeeuwHoxLeeuw, EDd. J. J. (2015). Internet panels, professional respondents, and data quality. Methodology, $11,81-88$.

35. Richardson, J., Chen, G., Khan, M. A., \& Iezzi, A. (2015). Can multi-attribute utility instruments adequately account for subjective well-being? Medical Decision Making, 35, 292-304.

36. Ratcliffe, J., Huynh, E., Chen, G., Stevens, K., Swait, J., Brazier, J., et al. (2016). Valuing the Child Health Utility 9D: Using profile case best worst scaling methods to develop a new adolescent specific scoring algorithm. Social Science \& Medicine, 157, 48-59.

37. Blome, C., \& Augustin, M. (2015). Measuring change in quality of life: Bias in prospective and retrospective evaluation. Value in Health, 18(1), 110-115.

38. Wu, J., Xie, S., He, X., Chen, G., Bai, G., Feng, D., et al. (2021). Valuation of SF-6Dv2 health states in China using time trade-off and discrete-choice experiment with a duration dimension. PharmacoEconomics, 39, 521-535.

Publisher's Note Springer Nature remains neutral with regard to jurisdictional claims in published maps and institutional affiliations. 